\title{
NEW ANALYTICAL MODEL TO GENERALIZE THE BARCELONA TEST USING AXIAL DISPLACEMENT
}

\author{
Pablo Pujadas $^{1}$, Ana Blanco ${ }^{2}$, Sergio Cavalaro ${ }^{3}$, Albert de la Fuente ${ }^{4}$, Antonio Aguado 5 \\ Department of Construction Engineering, Polytechnic University of Catalonia, Edifici C1, Campus Nord \\ UPC, Jordi Girona 1-3, 08034 Barcelona, Spain \\ E-mails: ${ }^{1}$ pablo.pujadas@upc.edu (corresponding author); ${ }^{2}$ ana.blanco@upc.edu; \\ ${ }^{3}$ sergio.pialarissi@upc.edu; ${ }^{4}$ albert.de.la.fuente@upc.edu; ${ }^{5}$ antonio.aguado@upc.edu \\ Received 16 Feb. 2012; accepted 16 Aug. 2012
}

\begin{abstract}
The Barcelona Test has proved to be very suitable for the systematic control of the tensile properties of Fibre Reinforced Concrete (FRC). Nevertheless, the need to measure the total circumferential opening displacement (TCOD) of the specimen entails the use of an expensive circumferential extensometer. In order to simplify the test, studies from the literature propose the use of the axial displacement of the press $(\delta)$ instead of the $T C O D$, obtaining empirical equations to correlate the energy estimated with both measurements. However, these equations are only valid for $\delta$ ranging from 1 to $4 \mathrm{~mm}$ and were adjusted based on the test results of just a few types of FRC. The verification of this formulation for other types of FRC shows an average error of 51.1\%, thus limiting the simplification proposed for the test. In this paper, a new analytical model to convert the $\delta$ into the TCOD is developed and validated for a wide range of FRC. Besides being applicable to the whole range of $\delta$, the new model provides a clear physical understanding of the main mechanism observed during the test and shows an average error of only $6.7 \%$, making it possible to simplify the Barcelona test.
\end{abstract}

Keywords: fibre reinforced concrete, analytical model, Double punching test, Barcelona test, toughness, tensile properties, circumferential extensometer, axial displacement.

Reference to this paper should be made as follows: Pujadas, P.; Blanco, A.; Cavalaro, S.; de la Fuente, A.; Aguado, A. 2013. New analytical model to generalize the Barcelona test using axial displacement, Journal of Civil Engineering and Management 19(2): 259-271.

\section{Introduction}

The recent publication of regulations and instructions (Walraven 2009; Blanco et al. 2013) about fibre reinforced concrete (FRC) has led to a significant increase in the application of this material for structural purposes in the past years (Serna et al. 2009; de la Fuente et al. 2012; Klein et al. 2011; Pujadas et al. 2012). This increase should be accompanied by the development of reliable and economical control methods for the characterization of the mechanical properties of the FRC, specially its post-cracking behavior (Di Prisco et al. 2009; Torrents et al. 2012).

The majority of methods currently used to characterize the post-cracking behaviour of FRC (de Montaignac et al. 2012) are based on bending tests of prismatic beams (Molins et al. 2006) loaded at mid span (EN 14651:2005 2005) or with two loads applied at one third of the span (NBN B 15-238 1992; ASTM C-1018 1997). All these test methods show large scattering (frequently over $20 \%$ ) and require the use of heavy specimens that are difficult to transport and set up (Molins et al. 2009; Parmentier et al. 2008).
To overcome these drawbacks, a modified double punching test known as Barcelona test was developed to measure the tensile behaviour of FRC (Molins et al. 2009). In the latter, two steel cylindrical punches arranged concentrically above and below the specimen transmit the load applied by the plates of the press that approach each other at a constant relative rate (Fig. 1a). This generates a radial tensile stress that causes between 2 and 4 radial cracks as well as the formation of two conical wedges at the specimen, as shown in Fig. 1b.

During the test, the load applied by the press and the total circumferential opening displacement $(T C O D)$ measured with a circumferential extensometer are recorded (UNE 83515:2010 2010). These results are then used to estimate FRC residual strength and toughness. The circumferential extensometer is expensive equipment, which is uncommon in most control laboratories. This fact limits considerably the application of the Barcelona test.

In order to simplify and make the test more accessible, an alternative measuring procedure was proposed by Carmona Malatesta et al. (2012) to 

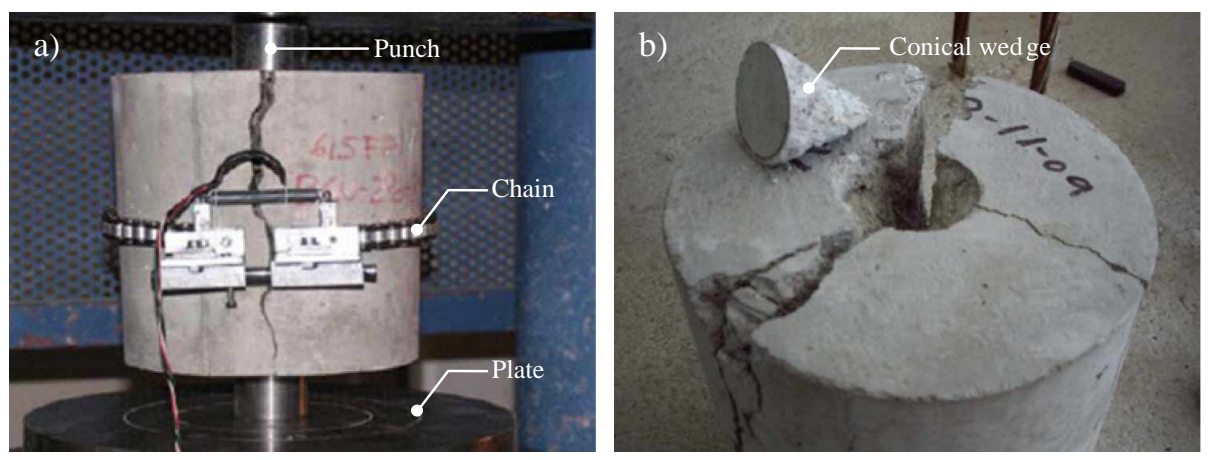

Fig. 1. Image of: a) Barcelona test setup and b) typical cracking pattern

avoid using the circumferential extensometer. The authors conducted an extensive laboratory research to derive an experimental correlation between the energy calculated with the TCOD and the energy calculated with the axial displacement of the press $(\delta)$. The results obtained by the authors indicate that this axial displacement measured in almost all presses may be used to estimate the toughness of the FRC, thus extending the application of the Barcelona test to conditions found in practically any control laboratory.

However, the correlations achieved by Carmona Malatesta et al. (2012) have severe limitations. For once, they relate the toughness calculated with the $T C O D$ and the obtained with the $\delta$, but not the direct measurement. Moreover, they are empirical and do not represent the physical mechanisms involved in the tensile failure of the FRC during the test.

It is important to remark that the correlations proposed are only valid for $\delta$ ranging from $1 \mathrm{~mm}$ to 4 $\mathrm{mm}$ and were obtained from the test results of just a few types of FRC. This clearly restricts its application to the types of fibres and concretes used in the experimental program conducted by Carmona Malatesta et al. (2012). In fact, the verification of the correlations for other types of FRC shows an average error of $51.1 \%$.

Given the considerable associate error, the correlations proposed by Carmona Malatesta et al. (2012) in reality do not allow the simplification proposed for the Barcelona test. In this context, a more general, straightforward and accurate model to convert the $\delta$ into the TCOD is yet required.

Taking that into account this paper pursues the following objectives:

- Analyse the theoretical mechanic and kinematic relation between the TCOD and the $\delta$ in order to provide a clear physical understanding of the main mechanism observed during the Barcelona test;

- Propose an analytical model for the whole extent of the test curve that allows a generalization of the Barcelona test by using the $\delta$ to determine the TCOD (not only the toughness as in the correlations from Carmona Malatesta et al. (2012));

- Validate the model proposed using the data from several experimental programs with different types of concrete as well as several types and amounts of fibres.

For that, based on the analysis of fracture mechanics of the Barcelona, a new analytical model is proposed. The model is then validated with a wide range of experimental data and compared with the correlation proposed by Carmona Malatesta et al. (2012). The results obtained indicate that the analytical model developed in this paper represents a considerable improvement of the correlations from the literature, showing an average error 7.6 times smaller (only 6.7\%) and making the simplification of the Barcelona test feasible.

\section{Fracture mechanics of the Barcelona test}

\subsection{General overview}

During the test, the specimen undergoes three different phases depending on its integrity and on the resistant mechanism. The Stage 1 coincides with the initial application of load. The internal stress generated is resisted by the concrete matrix that presents no major cracks (Fig. 2a). Once the stress reaches the tensile strength of the material, the specimen enters Stage 2. The upper and lower wedges are abruptly formed. According to several authors, these wedges present a conical shape with a diameter equal to that of the punches used in the test (Chen 1970; Bortolotti 1988; Molins et al. 2009; UNE 83515:2010 2010; Carmona Malatesta et al. 2012). Major cracks appear, dividing the specimen in parts that are kept together by the fibres bridging the cracks (Fig. 2b). As the cracks stabilize, the Stage 3 begins, following a kinematic mechanism that involves sliding between the conical wedge and the fragmented specimen, as illustrated in Fig. 2c.

Although some variations regarding the number and the opening of cracks may occur, for the purpose of the mathematical deductions a simplification is considered. As usually occurs during the test, it is assumed that the number of major cracks may be 


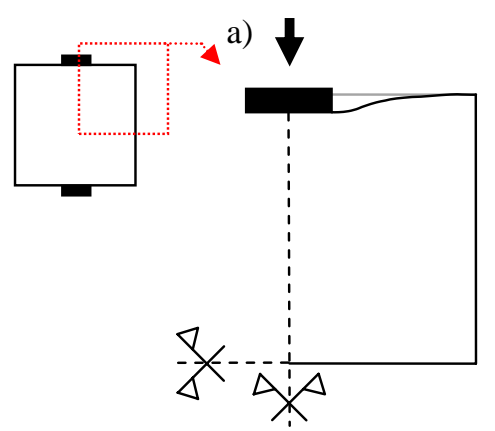

STAGE 1

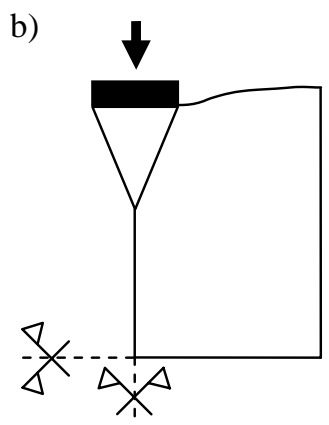

STAGE 2

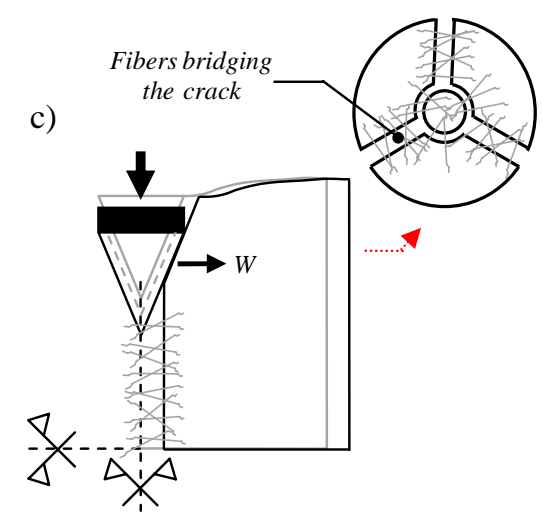

STAGE 3

Fig. 2. Different stages of the failure of a specimen in the Barcelona test

clearly identified and that the crack opening produces a uniform displacement of the fragmented specimen.

A more detailed description of the specificities and the expressions governing each stage are presented in the following sections to provide a better understanding on the physical mechanisms involved. To facilitate the comprehension of the mathematical deduction, the Stages 1 and 3 are presented before the Stage 2 .

\subsection{Stage 1}

Fig. 3a presents a typical curve obtained in the Barcelona test that relate the load applied (y axis) and $T C O D$ (x axis), whereas Fig. $3 \mathrm{~b}$ represents the corresponding curve in terms of the axial displacement $(\delta)$. In both cases, the stage 1 starts at the origin $(0.0)$ and extends up to the cracking of the specimen for a $T C O D$, a $\delta$ and a load equal to $T C O D_{c r}, \delta_{c r}$ and $F_{c r}$, respectively.

For low load levels there is a considerable difference between the TCOD and the $\delta$ measured. The latter show bigger values and an initial nonlinear tendency highlighted in Fig. 3b. This is attributed to the casting imperfections (Fig. 3c) and inherent instabilities of the test setup for low load levels. Once the coupling has taken place, the curve clearly shows an almost linear tendency that may be easily used to correct the initial nonlinearity.
In this stage, the TCOD measured is mainly attributed to the Poisson effect and the micro-cracking of the concrete matrix. As shown in Fig. 3a, the TCOD values obtained are small in comparison with those from other stages in which severe cracking has taken place. Therefore, with little margin to error, it is considered that the TCOD is 0 in stage 1 (see Eq. 1) regardless of the value of $\delta$ :

$$
T C O D=0 .
$$

\subsection{Stage 3}

This stage starts once the major cracks stabilize, corresponding to the stretch where the residual strength appear, that is, from the coordinates $\left(\delta_{R, 0}\right.$, $\left.F_{R, 0}\right)$ in Fig. $3 \mathrm{~b}$ on. In this case, the different concrete blocks formed by the radial cracks behave as rigid bodies connected with each other by the fibres bridging the cracks. The displacement of the punches forces the conical wedge to penetrate the specimen, causing a lateral displacement (d) of the adjacent concrete blocks. The equation that defines this mechanism may be obtained through a kinematic relation between the geometry of the conical wedge and the axial displacement $(\delta)$. It is assumed that the $n$ number of resulting blocks generated move as rigid
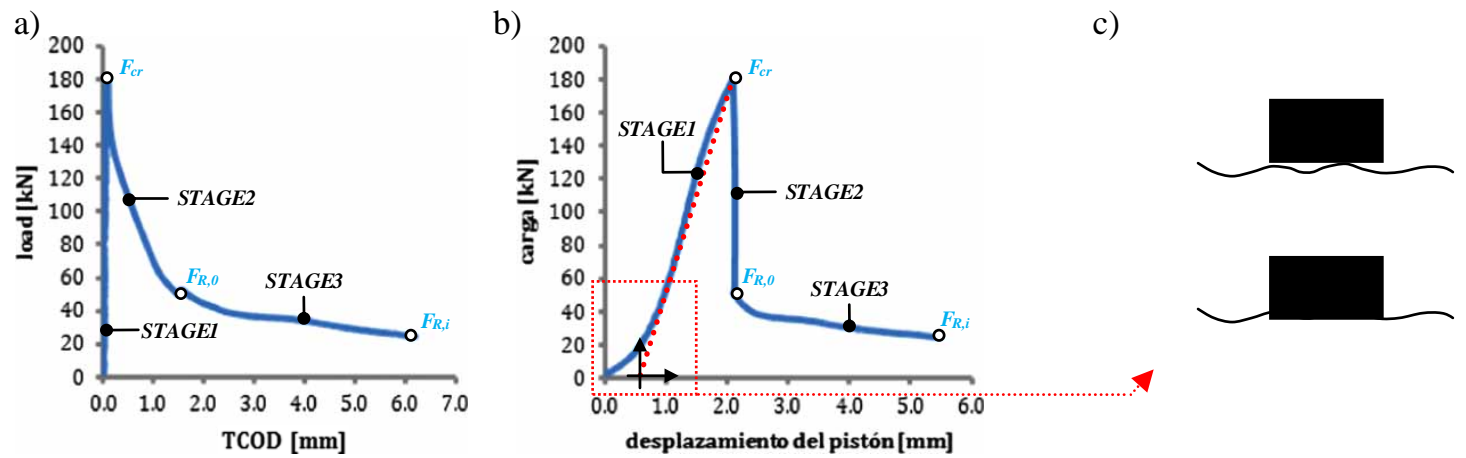

Fig. 3. Representation of: a) load vs. TCOD curve, b) load vs. axial displacement ( $\delta$ ) curve and c) detail of casting imperfection in surface of specimen 


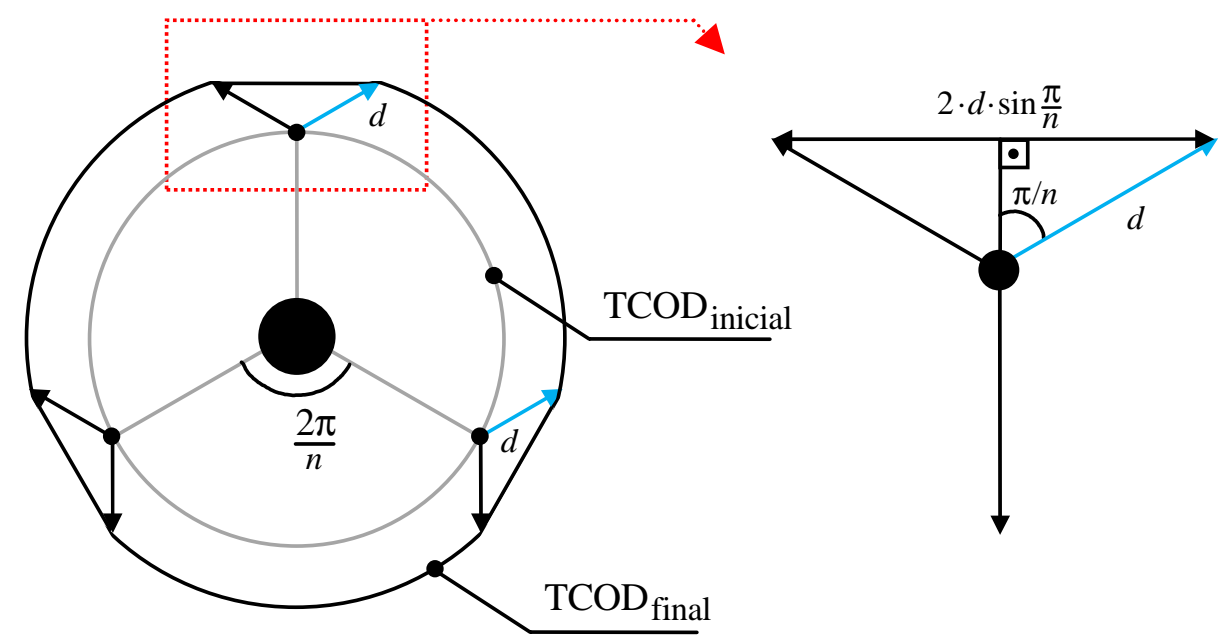

Fig. 4. Top view of the kinematic mechanism that governs Stage 3

bodies according to the lateral displacement vector $(d)$ indicated in Fig. 4.

In this context, the variation of the TCOD measured due to the opening of one of the cracks may be considered as the component of the lateral displacement vector $(d)$ along the perimeter of the blocks. This is represented mathematically in Eq. (2), obtained through a simple trigonometrical relation (see Fig. 4). If similar displacements occur in all blocks, the total variation of the TCOD ( $\triangle(T C O D)$ may be calculated by the product of the variation in each crack (Eq. 2) and the number of cracks $(n)$ formed in Stage 3, as shown in Eq. (3):

$$
\begin{aligned}
\Delta(T C O D)_{1 \text { crack }} & =2 d \sin \frac{\pi}{n} ; \\
\Delta(T C O D) & =2 n d \sin \frac{\pi}{n} .
\end{aligned}
$$

Fig. 5 illustrates a front view of the test and the kinematic mechanism according to which the penetration of the conical wedge causes the lateral displacement (d) of the concrete blocks. Notice that the magnitude of $d$ is related to the axial displacement of the conical wedge $\left(\Delta \delta_{c}\right)$, the diameter $(a)$ and the height $(l)$ of the conical wedge.
Applying the Thales theorem to the triangles defined by the movement of the wedge allow the definition of Eq. (4) to estimate the lateral displacement $(d)$ :

$$
\frac{a / 2}{l}=\frac{a / 2+d}{l+\Delta \delta_{c}} \rightarrow . d=\frac{a \Delta \delta_{c}}{2 l} .
$$

It is important to remark that the press usually records the total variation of the axial displacement $(\Delta \delta)$ that should equal the sum of the vertical displacements of the punches $\left(\Delta \delta_{c}\right)$ located at the top and at the bottom of the specimen.

Assuming a symmetric movement, each punch should be responsible for half of the total displacement (Eq. (5)). By combining Eqs (4) and (5), Eq. (6) is obtained to estimate the lateral displacement of the blocks $(d)$ :

$$
\begin{aligned}
\Delta \delta_{c} & =\frac{\Delta \delta}{2} ; \\
d & =\frac{a \Delta \delta}{4 l} .
\end{aligned}
$$

The substitution of Eq. (6) in Eq. (2) yields Eq. (7) that should be used for the assessment of the variations in the $T C O D$ depending on the variation of
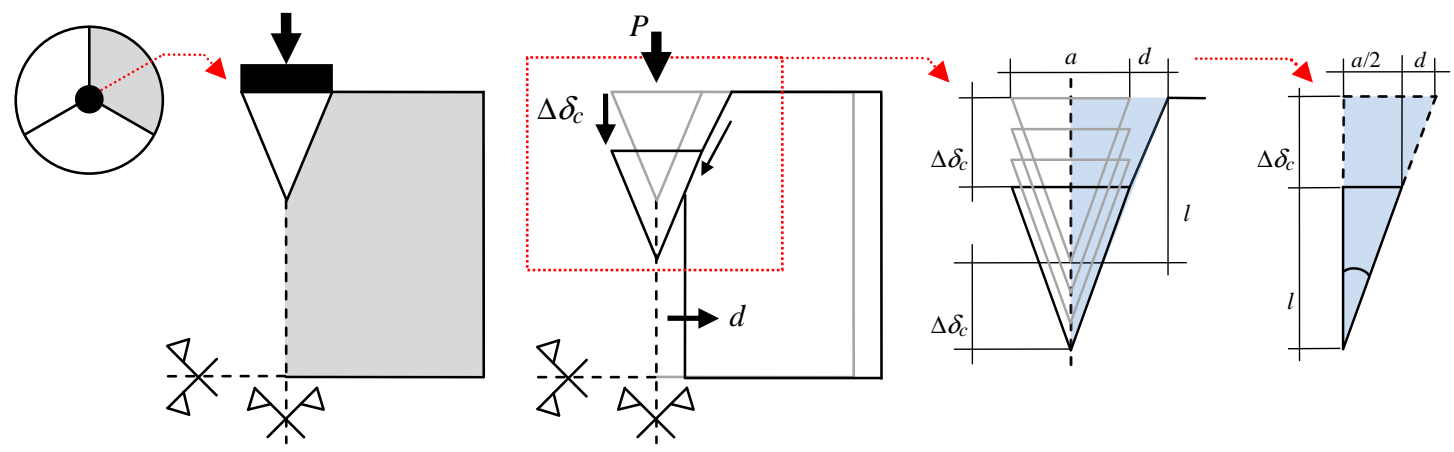

Fig. 5. Front view of the kinematic mechanism that governs Stage 3 
the axial displacement $(\Delta \delta)$ of the press. Notice that, in Stage 3, there is a linear relation between both parameters:

$$
\Delta(T C O D)=n \frac{a}{2 l} \sin \frac{\pi}{n} \Delta \delta \rightarrow \frac{\Delta(T C O D)}{\Delta \delta}=n \frac{a}{2 l} \sin \frac{\pi}{n} .
$$

According to Eq. (8), the absolute TCOD in Stage 3 is calculated by the sum of the variation $\triangle(T C O D)$ and the TCOD measured by the end of Stage $2\left(T C O D_{\max , S t 2}\right)$, which will be deducted in the next section. In this case, the TCOD may be estimated in Eq. (9) obtained after substituting Eq. (7) in Eq. (8) and considering that the variation of the axial displacement $(\Delta \delta)$ is given by $\left(\delta-\delta_{R, 0}\right)$ in Stage 3:

$$
\begin{aligned}
& T C O D=\Delta(T C O D)+T C O D_{\max , s t 2} ; \\
& T C O D=n \frac{a}{2 l} \sin \frac{\pi}{n}\left(\delta-\delta_{R, 0}\right)+T C O D_{\max , s t 2} .
\end{aligned}
$$

\subsection{Stage 2}

The Stage 2 marks the transition between the mechanisms described in Section 2.2 and 2.3 for Stages 1 and 3 , respectively. It is represented in the stretch that extends from point $\left(\delta_{c r}, F_{c r}\right)$ to the point $\left(\delta_{R, 0}, F_{R, 0}\right)$ in Fig. 3b. To better understand this transition, consider the case of the Barcelona test performed in concrete specimens with a very small fibre amount that lead to a residual strength of approximately 0 . If the specimen was cracked from the beginning of the test, it would follow only Stage 3 according to Eq. (8) that relates $T C O D$ and $\delta$ (dotted line in Fig. 6a).

In reality, however, the specimen is not cracked at the beginning of the test, so that initially it would behave according to Stage 1, showing an axial displacement of the press $(\delta)$ that increases whereas the $T C O D$ remains close to 0 (Fig. 6a). Once the stress reaches the maximum tensile strength of plain concrete, cracks would appear rendering inactive the existing resistant mechanism of Stage 1. Since the amount of fibre is small, there would be almost no restriction to the crack opening. Consequently, the $T C O D$ would increase abruptly until the equilibrium, reaching the value $T C O D_{0, A}$ corresponding to the new resistant mechanism from Stage 3. In fact, the value of $T C O D_{0, A}$ may be estimated using Eq. (9) and the axial displacement of the stretch with residual strength $\left(\delta_{R, 0}\right)$, as shown in Eq. $(10)$ :

$$
\operatorname{TCOD}_{0, A}=n \frac{a \delta_{R, 0}}{2 l} \sin \frac{\pi}{n} .
$$

Suppose now that the same test was performed in a specimen with an intermediate fibre content that led to a softening behaviour, as shown in Fig. 6b. In this situation, a similar outcome would be expected. Nevertheless, due to the greater amount of fibre, a higher restriction to the crack opening would happen so that the equilibrium with Stage 3 would be reached for a $T C O D_{0, B}$ smaller than $T C O D_{0, A}$ (Fig. 6b). From this point on, the specimen would follow the Eq. (7) from Stage 3.

In order to obtain $T C O D_{0, B}$ it is assumed that the energy released in the change of resistant mechanism from Stages 1 to 3 is proportional to the drop on the maximum strength observed in the test (see Fig. $3 b$ ). This may be represented mathematically by Eq. (11). Notice that the latter is also valid for the specimen with a very small amount of fibre (Fig. 6a). In such case, the $F_{R, 0}$ is 0 and the $T C O D_{0, B}$ becomes $T C O D_{0, A}$ :

$$
\operatorname{TCOD}_{0, B}=\operatorname{TCOD}_{0, A}\left(1-\frac{F_{R, 0}}{F_{c r}}\right) .
$$

The generalization of Eq. (11) for any result in Stage 2 is represented in Eq. (12) by substituting $F_{R, 0}$ by the load applied $(F)$. After combining Eqs (10) and (12), Eq. (13) is obtained to estimate the TCOD in Stage 2:

$$
\begin{gathered}
T C O D=T C O D_{0, A}\left(1-\frac{F}{F_{c r}}\right) ; \\
T C O D_{0, B}=n \frac{a \delta_{R, 0}}{2 l} \sin \frac{\pi}{n}\left(1-\frac{F_{R, 0}}{F_{c r}}\right) .
\end{gathered}
$$

The same equation remains valid even if the FRC presented a hardening behaviour. In this case, by definition the cracking load would be equal to the initial residual load $\left(F_{c r}=F_{R, 0}\right)$. Consequently, the $T C O D$ measured in Stage 2 according to Eq. (13) a)

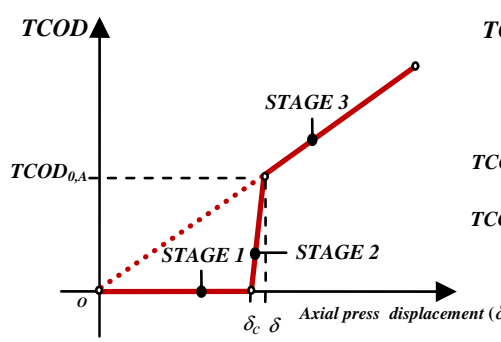

b)

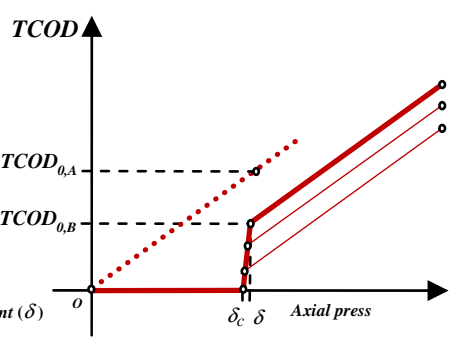

c)

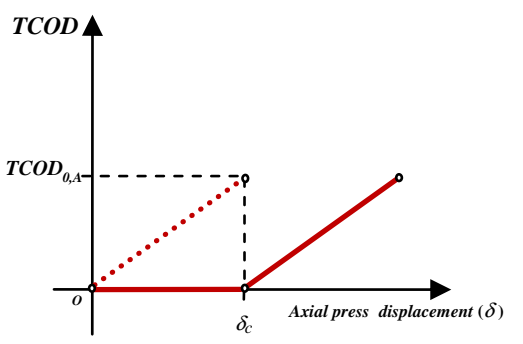

Fig. 6. Curves that relate $T C O D$ and $\delta$ for FRC with: a) almost no residual strength; b) softening; and c) hardening 
should be 0 . In this context, the curve that relates the $T C O D$ and $\delta$ should approximate the one shown in Fig. 6c. It is important to remark that the TCOD measured by the end of Stage $2\left(T C O D_{\max , S t 2}\right)$ is calculated in Eq. (14), obtained after substituting in Eq. (13) both the limit values of the axial displacement $\left(\delta_{R, 0}\right)$ and the load applied $\left(F_{R, 0}\right)$ in this stage:

$$
T C O D_{\text {max }, \text { stage } 2}=n \frac{a \delta_{R, 0}}{2 l} \sin \frac{\pi}{n}\left(1-\frac{F_{R, 0}}{F_{c r}}\right) .
$$

\section{Model to convert axial displacement $(\delta)$ to $T C O D$}

Based on the development performed throughout the paper, the correlation between TCOD and $\delta$ can be described by the tri-linear model presented below. The first two correspond to the Eqs (1) and (13) that represent the behaviour in Stages 1 and 2, respectively. On the other hand, the last equation represents the behaviour in Stage 3, which was obtained after combining Eqs (14) and (11):

$$
\left\{\begin{array}{lc}
T C O D=0 & \delta \leq \delta_{c r} \\
T C O D=n \frac{a \delta_{R, 0}}{2 l} \sin \frac{\pi}{n}\left(1-\frac{F_{R, 0}}{F_{c r}}\right) & \delta_{c r}<\delta<\delta_{R, 0} \\
T C O D=n \frac{a}{2 l} \sin \frac{\pi}{n}\left(\delta-\delta_{c r}+\delta_{R, 0}\left(1-\frac{F_{R, 0}}{F_{c r}}\right)\right) \delta \geq \delta_{R, 0} .
\end{array}\right.
$$

The application of the model proposed is direct and valid for the whole extent of the load-axial displacement $(\delta)$ curve, as shown in Fig. 7. It depends only on the definition of 6 physical input parameters: $F_{c n}, \delta_{c n}, F_{R, 0}, \delta_{R, 0}, n$, and $l$. All these parameters are either obtained during the Barcelona test or assessed afterwards upon a visual inspection of the specimen. Then, the equations defined previously are used to convert each value of $\delta$ to a corresponding TCOD. This allows the definition of the resulting load-TCOD curve.

\subsection{Length of the conical wedge $(l)$}

The dimension of the conical wedge formed during the test is a topic subject to a certain controversy. It is accepted that the cracking surface of the wedge is determined by the friction angle of the material, represented by $\kappa$ in Fig. 8. The latter depends of the roughness of the contact surfaces (Fig. 8b), the interlocking effect between the aggregates used in the concrete and the presence of fibres crossing the contact surface. The latest versions of some structural design codes consider average values of the friction angle $(\kappa)$ between $50^{\circ}$ and $60^{\circ}$ (Sainz 2010; Carmona Malatesta et al. 2012) for monolithic plain concrete.

The length $(l)$ of the conical wedge may be obtained using this angle and a simple trigonometric relation shown in Eq. (16). In this sense, the range recommended for $\kappa$ corresponds to a length $(l)$ between 22 and $33 \mathrm{~mm}$ for plain concrete. However, it has been experimentally demonstrated that the addition of fibres increases both cohesion and internal friction angle of concrete ( $\kappa$ ) (Sainz 2010):

$$
l=\frac{a}{2} \tan \theta .
$$

As shown in Fig. 9, the conical wedges extracted from specimens subjected to the Barcelona test consistently indicate a length around $40 \mathrm{~mm}$. This corresponds to a friction angle $(\kappa)$ of approximately 65 , a value slightly bigger than the upper limit of the range defined in the literature. Such difference may be attributed to variation in the testing conditions and to the addition of fibres, which are expected to increase $\kappa$ (Sainz 2010). Therefore, in the absence of more detailed experimental data, a length $(l)$ of the conical wedge equal to $40 \mathrm{~mm}$ will be assumed for the estimations performed.

\section{Validation with experimental results}

Although the method proposed appear to be simple and logical, it is necessary to check its validity against real experimental data. For that, an extensive study of

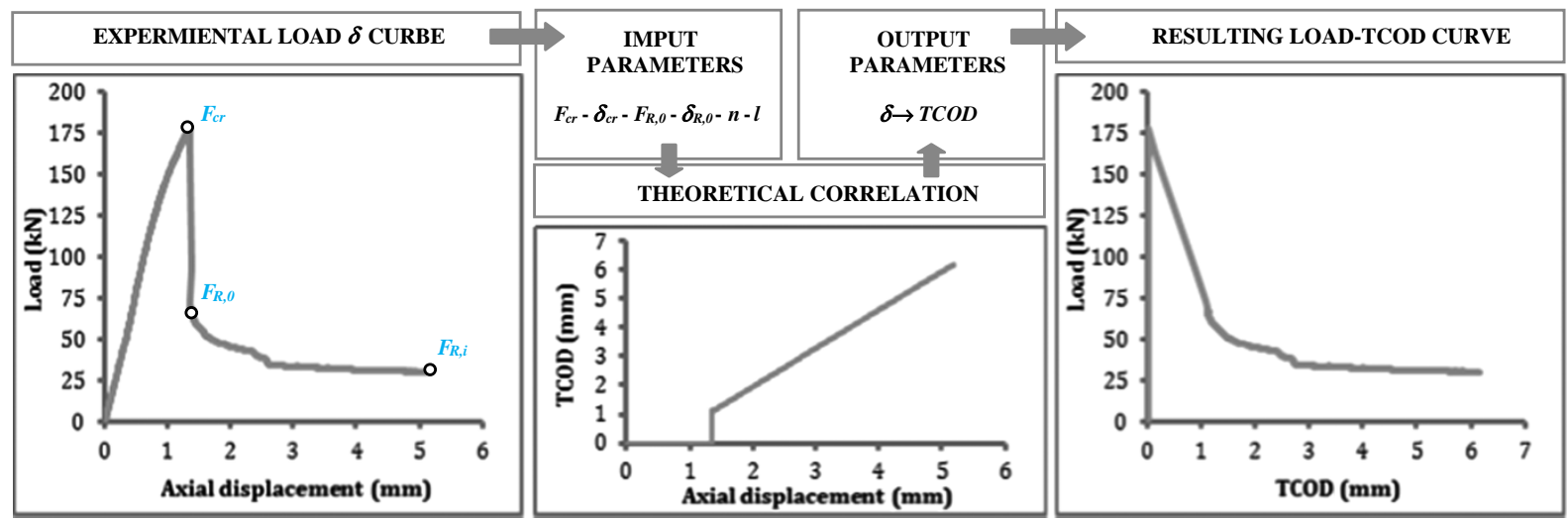

Fig. 7. Overview of the work philosophy to correlate TCOD and axial displacement $(\delta)$ 


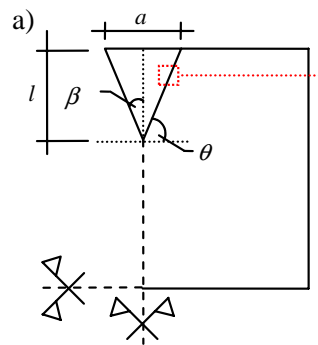

b)

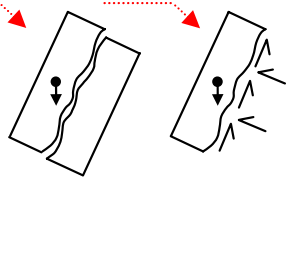

c)

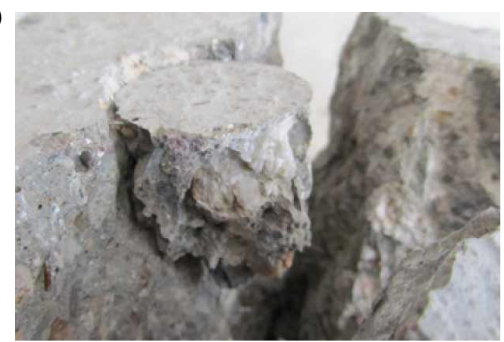

Fig. 8. Details of: a) friction angle $\theta$; b) roughness of contact surface; and c) conical wedge observed in a real specimen

the Barcelona test was performed using the data obtained from previous experimental programs conducted at the Laboratory of Technology Structures of the Universitat Politècnica de Catalunya (UPC).

In order to assure a complete and balanced validation of the model, a wide range of FRC in terms of strength (with softening and hardening), fibre type and fibre content was considered.

Results from 5 concrete mixes were used: 2 FRC with polypropylene fibres (PF); 2 FRC with steel fibres (SF); and 1 Ultra-High Performance Fibre Reinforced Concrete (UHPFRC) with steel microfibres (SMF). The fibre content added and the nomenclature adopted to distinguish these concretes are presented in Table 1. The number that appears in the place of the letter $\mathrm{N}$ in the nomenclature indicates the reference of the specimen tested. The main characteristics of the fibres used are presented in Table 2 .

The Barcelona test was performed in all specimens following the recommendations of (UNE $83515: 2010$ 2010). Both the TCOD and axial displacement of the press $(\delta)$ were measured during the test. According to the validation procedure defined, initially the parameters required for the application of the model proposed in this paper are identified (see Table 3 ). The values of $F_{c r}, \delta_{c r}, F_{R, 0}$ and $\delta_{R, 0}$ were estimated directly in the curve load-axial displacement of each specimen. A length of the conical wedge $(l)$ of $40 \mathrm{~mm}$ was used for all specimens since the direct measurement could not be performed. The assumed number of cracks was 3, according to Molins et al. (2006). This approach was adopted in order to avoid any biased analysis in favour of the new model developed in this paper.

The data provided in Table 3 is used in the model from section 3 to convert the axial displacement $(\delta)$ into the TCOD. Finally, the latter is compared with the actual TCOD measured during the test of each specimen. Figs 10 to 14 illustrates the results of the application of the new model proposed in one specimen representative of the different types of concretes tested. In every figure, the first graph shows the curve of the load applied and the axial displacement measured $(\delta)$ during the test. The second graph presents the curve relating the axial displacement $(\delta)$ and the TCOD obtained in the test and estimated with the model proposed in Section 4. Likewise, the third graph compares the final TCOD-load curve obtained experimentally and the one estimated theoretically with the new model.

Despite the assumptions concerning the parameters $n$ and $l$, a very good fit is observed between the experimental and the theoretical results. It is evident that the model proposed in Section 4 is capable of estimating with good accuracy the TCOD of the specimens, regardless of the type of concrete (conventional FRC or UHPFRC), the fibre used (steel or plastic, micro or macro) or the ductility of the material. This was observed for the whole extent of the curves, including $T C O D$ ranging from 0 up to 5 $\mathrm{mm}$.

The new model succeeds in estimating the abrupt increase of the TCOD observed in Stage 2 that becomes more considerable as the fibre content reduces. It is also capable of accounting for the
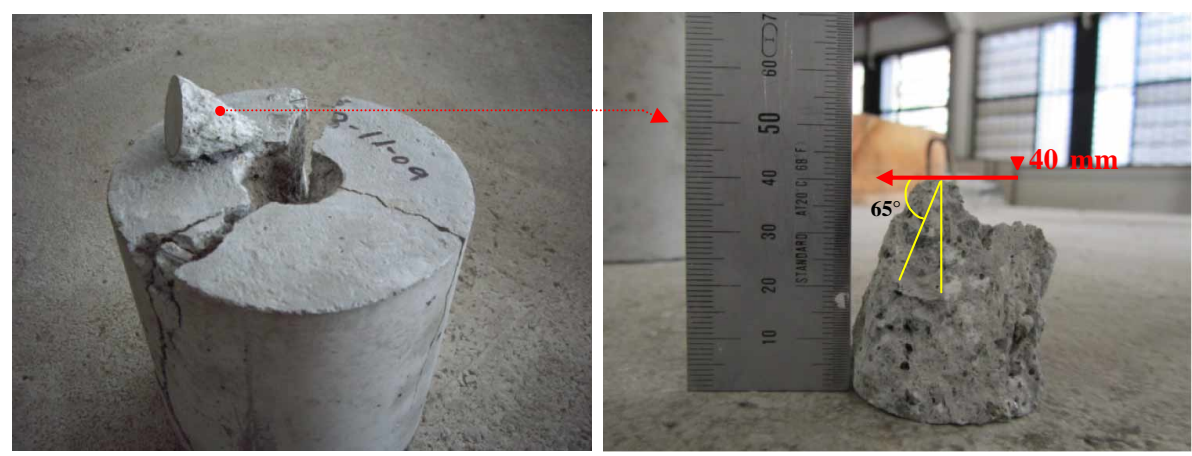

Fig. 9. Length $(l)$ and friction angle $(\theta)$ of conical wedge extracted from specimen 
Table 1. Types of concrete

\begin{tabular}{lllr}
\hline Nomenclature & $\begin{array}{r}\text { Type of } \\
\text { concrete }\end{array}$ & $\begin{array}{c}\text { Fiber } \\
\text { type }\end{array}$ & \multicolumn{1}{c}{$\begin{array}{c}\text { Fiber } \\
\text { content }\end{array}$} \\
\hline FRC_PF_5_N & FRC & PF & $5 \mathrm{~kg} / \mathrm{m}^{3}$ \\
FRC_PF_9_N & FRC & PF & $9 \mathrm{~kg} / \mathrm{m}^{3}$ \\
FRC_SF_60_N & FRC & SF1 & $60 \mathrm{~kg} / \mathrm{m}^{3}$ \\
FRC_SF_40_N & FRC & SF1 & $40 \mathrm{~kg} / \mathrm{m}^{3}$ \\
UHPFRC_SMF_130_N & UHPFRC & SMF & $130 \mathrm{~kg} / \mathrm{m}^{3}$ \\
UHPFRC_SMF_157_N & UHPFRC & SMF & $157 \mathrm{~kg} / \mathrm{m}^{3}$ \\
UHPFRC_SMF_170_N & UHPFRC & SMF & $170 \mathrm{~kg} / \mathrm{m}^{3}$ \\
\hline
\end{tabular}

hardening behaviour of the UHPFRC with steel microfibers. As expected, in this case the residual load $\left(F_{R, 0}\right)$ equals the cracking load $\left(F_{c r}\right)$ so that the $T C O D$ measured in Stage 2 is 0 . Consequently, the curve relating the TCOD and $\delta$ approximates the one shown in Fig. 6c.

In Figs 15 to 17 the relations between TCOD values measured and predicted with the new model are presented for each series. In Fig. 17b, the data from all specimens are presented together. In every graph a linear regression is performed and the $\mathrm{R} 2$ is calculated.

These results reinforce the good accuracy of the model proposed since the slopes of all trending lines are quite close to 1 with $\mathrm{R}^{2}$ values of approximately 1 ,
Table 2. Fibre characteristics (data provided by the manufacturer)

\begin{tabular}{|c|c|c|c|}
\hline \multirow[b]{2}{*}{ Characteristics } & \multirow{2}{*}{$\begin{array}{c}\text { Polypropylene } \\
\text { Fiber } \\
\text { PF }\end{array}$} & \multicolumn{2}{|c|}{ Steel Fiber } \\
\hline & & SF & MSF \\
\hline Length (mm) & $48 \mathrm{~mm}$ & 50 & 12 \\
\hline $\begin{array}{l}\text { Equivalent diameter } \\
\text { (mm) }\end{array}$ & - & 0.62 & 0.20 \\
\hline Aspect ratio & - & 80 & 60 \\
\hline Tensile strength (MPa) & 550 & 1270 & \\
\hline $\begin{array}{l}\text { Modulus of elasticity } \\
(\mathrm{GPa})\end{array}$ & 10.0 & 210 & \\
\hline Number of fibers per $\mathrm{kg}$ & $>35.000$ & 8.100 & \\
\hline
\end{tabular}

regardless of the type of concrete, fibre and postcracking behaviour. In this sense, the trending line with the lowest slope value corresponds to the series FRC_PF_5_N, which is the series with the lower fibre content and consequently with a lower average value of residual strength $\left(F_{R, 0}\right)$.

\section{Comparison with model from literature}

The toughness of the FRC is defined as the capacity of the material to absorb energy. In the Barcelona test,

Table 3. Input parameters used to predict the TCOD in the Barcelona test

\begin{tabular}{|c|c|c|c|c|c|c|}
\hline Specimen & Ffis $[\mathrm{kN}]$ & $\delta$ fis [mm] & Fres $[\mathrm{kN}]$ & Sres $[\mathrm{mm}]$ & $n[-]$ & $l[\mathrm{~mm}]$ \\
\hline FRC_PF_5_1 & 179.98 & 1.48 & 53.50 & 1.52 & 4 & 40 \\
\hline FRC_PF_5_2 & 177.33 & 1.36 & 83.22 & 1.41 & 4 & 40 \\
\hline FRC_PF_5_3 & 183.82 & 1.40 & 61.61 & 1.45 & 3 & 40 \\
\hline FRC_PF_5_4 & 178.40 & 1.34 & 73.20 & 1.37 & 4 & 40 \\
\hline FRC_PF_5_5 & 164.60 & 1.31 & 86.00 & 1.34 & 3 & 40 \\
\hline FRC_PF_5_6 & 174.50 & 0.98 & 77.50 & 1.20 & 3 & 40 \\
\hline FRC_PF_9_1 & 152.60 & 1.36 & 96.00 & 1.43 & 4 & 40 \\
\hline FRC_PF_9_2 & 149.50 & 1.70 & 84.50 & 1.82 & 3 & 40 \\
\hline FRC_PF_9_3 & 140.95 & 1.57 & 81.90 & 1.59 & 3 & 40 \\
\hline FRC_PF_9_4 & 151.90 & 1.76 & 88.00 & 1.79 & 4 & 40 \\
\hline FRC_PF_9_5 & 155.30 & 1.85 & 87.79 & 1.85 & 3 & 40 \\
\hline FRC_PF_9_6 & 155.30 & 2.36 & 71.71 & 2.39 & 3 & 40 \\
\hline FRC_SF_60_5 & 181.80 & 1.04 & 167.00 & 1.05 & $3 *$ & 40 \\
\hline FRC_SF_60_6 & 178.80 & 1.44 & 162.00 & 1.52 & $3 *$ & 40 \\
\hline FRC_SF_40_1 & 150.50 & 1.23 & 112.50 & 1.26 & $3^{*}$ & 40 \\
\hline FRC_SF_40_3 & 157.70 & 1.33 & 116.00 & 1.45 & $3 *$ & 40 \\
\hline FRC_SF_40_4 & 157.70 & 1.13 & 119.00 & 1.19 & $3^{*}$ & 40 \\
\hline FRC_SF_40_5 & 158.37 & 1.37 & 110.00 & 1.39 & $3^{*}$ & 40 \\
\hline FRC_SF_40_6 & 151.40 & 1.33 & 105.00 & 1.36 & $3^{*}$ & 40 \\
\hline UHPFRC_SMF_130_1 & 323.00 & 1.06 & 323.00 & 1.06 & $3^{*}$ & 40 \\
\hline UHPFRC_SMF_130_2 & 325.00 & 1.16 & 325.00 & 1.16 & $3 *$ & 40 \\
\hline UHPFRC_SMF_157_1 & 319.54 & 1.20 & 319.54 & 1.20 & $3 *$ & 40 \\
\hline UHPFRC_SMF_157_2 & 323.00 & 0.99 & 323.00 & 0.99 & $3^{*}$ & 40 \\
\hline UHPFRC_SMF_170_1 & 324.00 & 0.95 & 324.00 & 0.95 & $3^{*}$ & 40 \\
\hline
\end{tabular}

$\left(^{*}\right)$ no information about the number of cracks was disposed ( $n=3$ was adopted as reference) 

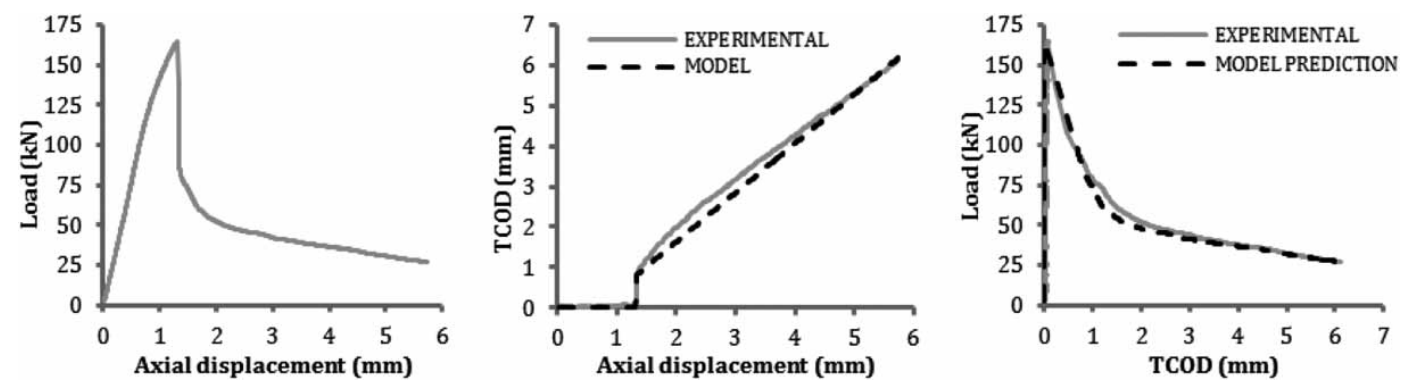

Fig. 10. Results for FRC_PF_5_5
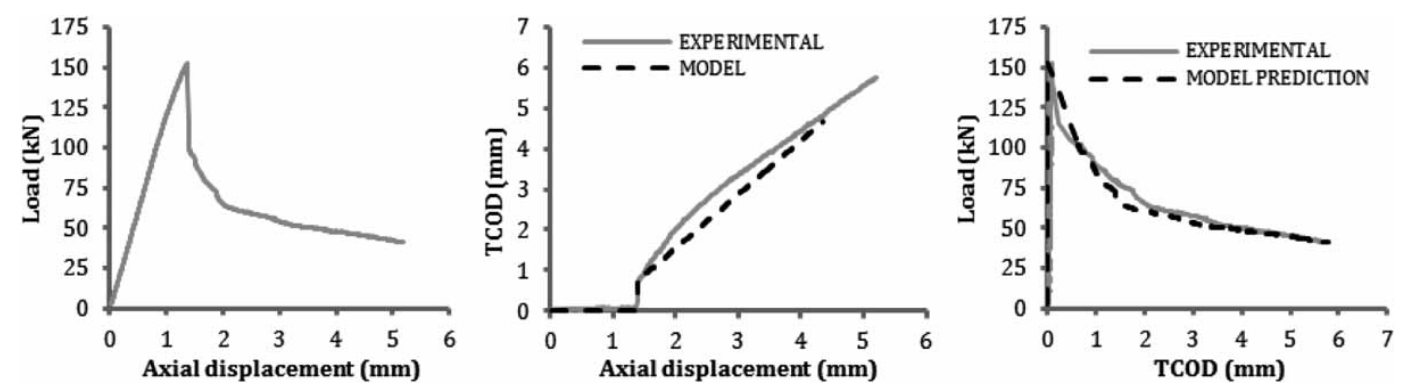

Fig. 11. Results for FRC_PF_9_1
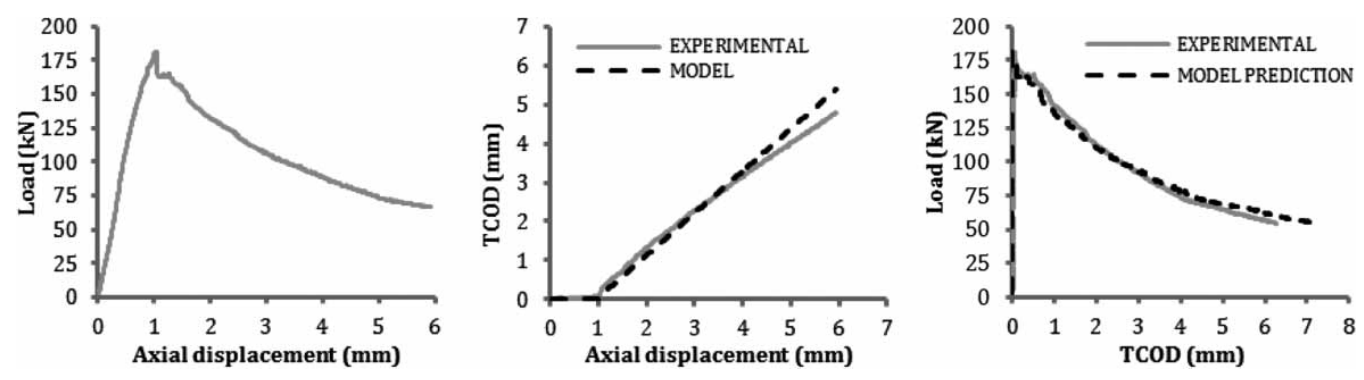

Fig. 12. Results for FRC_SF_60_5
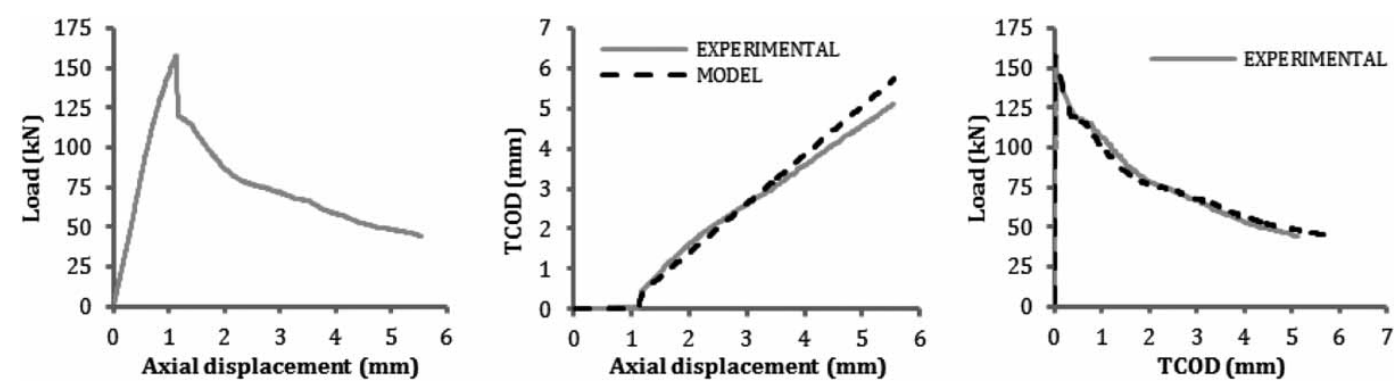

Fig. 13. Results for FRC_SF_40_4
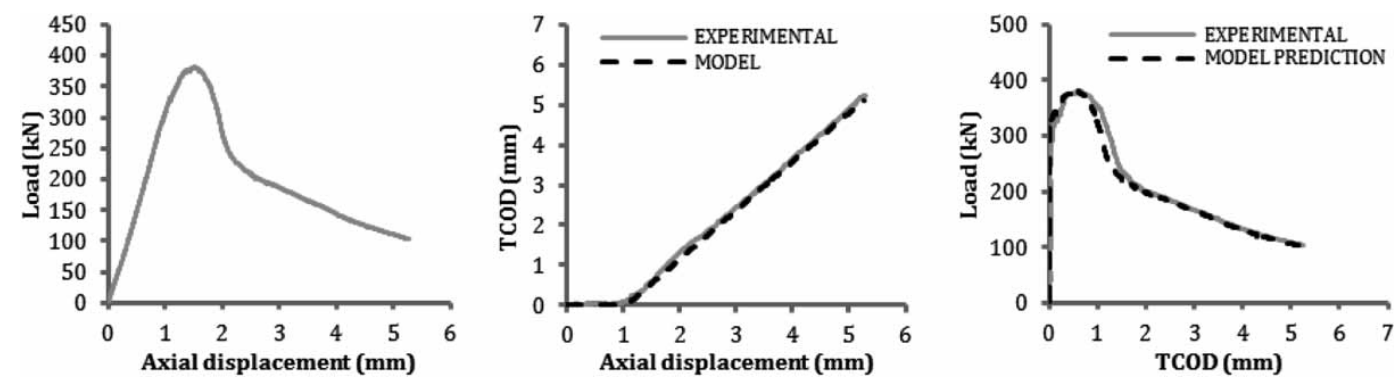

Fig. 14. Results for UHPFRC_SMF_130_1 

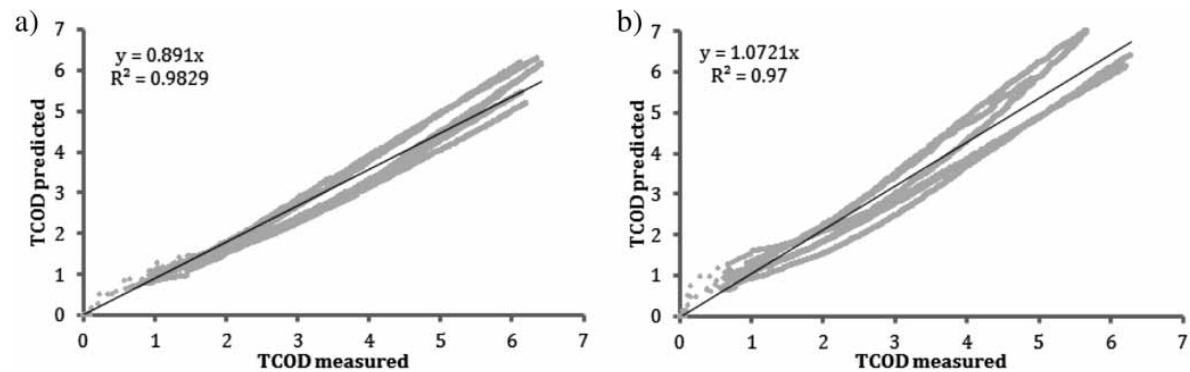

Fig. 15. Measured and predicted $T C O D$ for: a) FRC_PF_5_N and b) FRC_PF_9_N
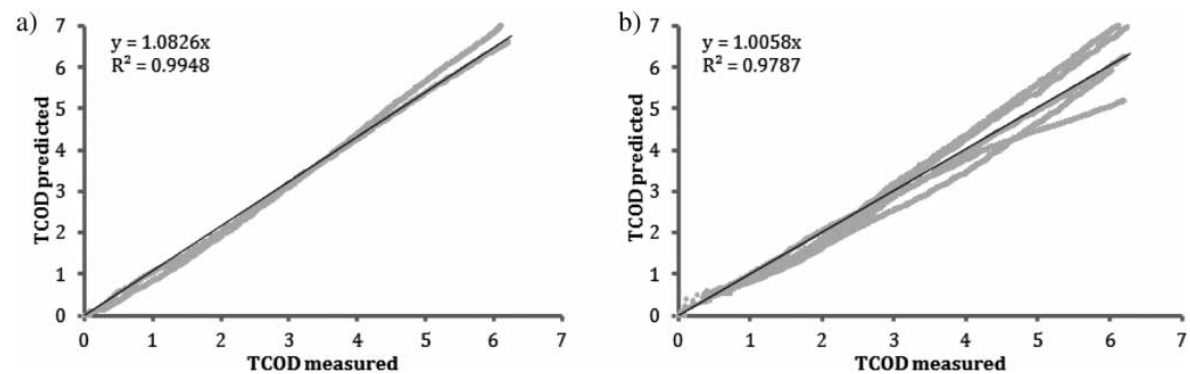

Fig. 16. Measured and predicted $T C O D$ for: a) FRC_SF_60_N and b) FRC_SF_40_N
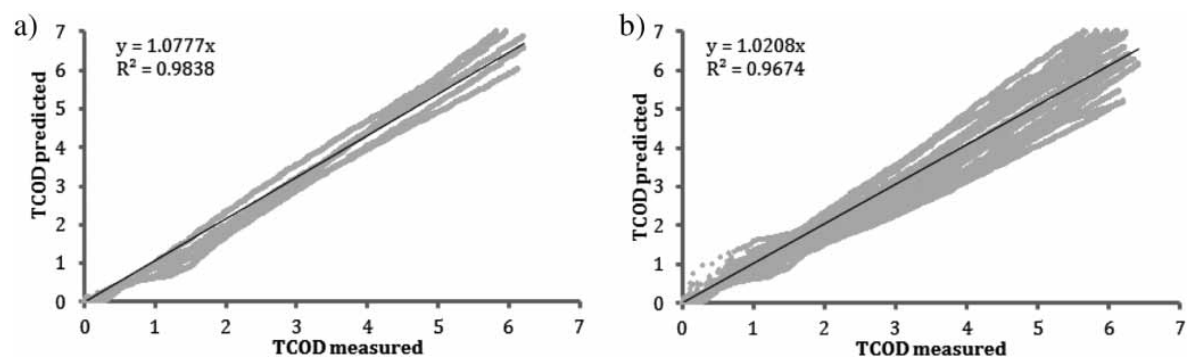

Fig. 17. Measured and predicted $T C O D$ for: a) UHPFRC_SMF and b) for all data

two different types of toughness may be estimated depending on the displacement used. If the axial displacement $(\delta)$ is considered, this property is calculated according with Eq. (17) that represents the area below the graph load $(F)$ - axial displacement $(\delta)$. On the other hand, if the TCOD is considered, the toughness is calculated in Eq. (18), which gives the area below the graph load $(F)-T C O D$ :

$$
\begin{aligned}
T(\delta) & =\int_{0}^{\delta} P(\delta) d \delta \\
E(T C O D) & =\int_{0}^{T C O D} P(T C O D) d(T C O D) .
\end{aligned}
$$

Recent studies attempted to correlate the results of toughness calculated with circumferential displacement $E(T C O D)$ and the obtained with the axial displacement $T(\delta)$.

According to Carmona Malatesta et al. (2012), a linear relation between both values exists for the range of $\delta$ between 1.0 and $4.0 \mathrm{~mm}$. This relation is found by means of a linear regression using the date obtained by the author in an experimental program.

The relation between $T(\delta)-E(T C O D)$ were calculated for different FRC according the empirical formulation proposed by Carmona Malatesta et al. (2012) and according the new analytical model proposed in this paper. The results obtained are presented together with the experimental results for some specimens in Figs 18 and 19. It is important to remark that the other specimens follow one similar to the observed in these figures.

In all cases analysed the correlations from Carmona Malatesta et al. (2012) leads to a considerable overestimation of the $E(T C O D)$, being valid only for the final part of the curves. On the other hand, the formulation proposed in this paper shows a good fit with the experimental result for the whole extent of the curve.

In order to quantify the improvement obtained, Table 4 presents the predicted values of $E(T C O D<4$ $\mathrm{mm}$ ) for both models and the experimental results. 

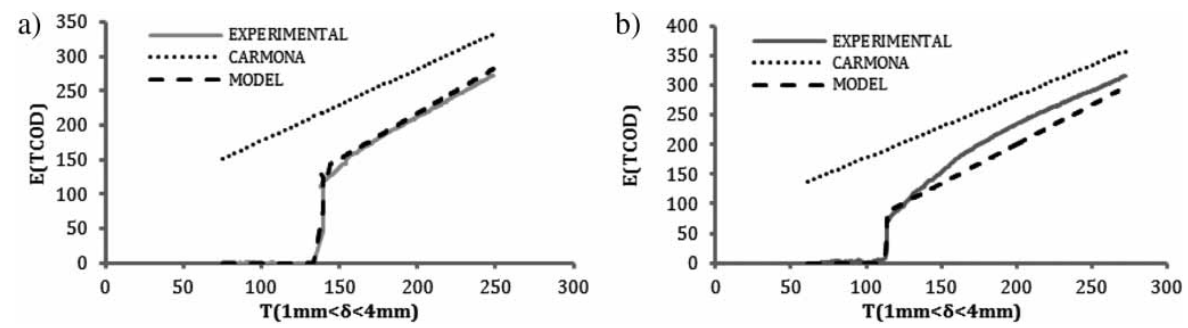

Fig. 18. Relation between $T(\delta)-E(T C O D)$ : a) FRC_PF_5_5 and b) FRC_PF_9_1
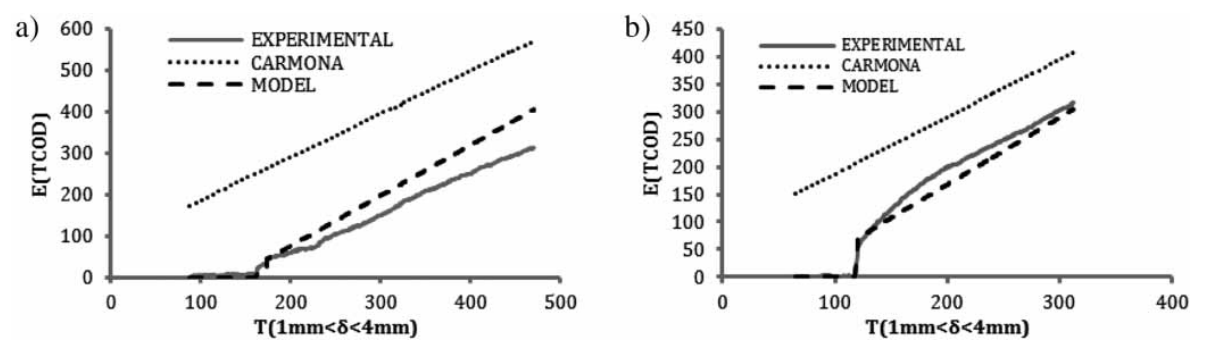

Fig. 19. Relation between $T(\delta)-E(T C O D)$ : a) FRC_SF_60_6 and b) FRC_SF_40_5

Table 4. Comparison of experimental and predicted values of $E(T C O D<4 \mathrm{~mm})$

\begin{tabular}{|c|c|c|c|c|c|c|c|}
\hline \multirow[b]{3}{*}{ Specimen } & \multirow[b]{3}{*}{ EXP. } & \multicolumn{6}{|c|}{$E(T C O D<4 \mathrm{~mm})[\mathrm{kN} \mathrm{mm}]$} \\
\hline & & \multicolumn{3}{|c|}{ Carmona Malatesta et al. (2012) } & \multicolumn{3}{|c|}{ New Model } \\
\hline & & PRED. & ERR. $(\%)$ & AV. ERR. $(\%)$ & PRED. & ERR. $(\%)$ & AV. ERR. $(\%)$ \\
\hline FRC_PF_5_1 & 278.73 & 320.17 & -14.87 & 26.24 & 280.11 & -0.50 & 5.38 \\
\hline FRC_PF_5_2 & 272.67 & 332.43 & -21.92 & & 278.43 & -2.11 & \\
\hline FRC_PF_5_3 & 264.96 & 314.15 & -18.57 & & 248.32 & 6.28 & \\
\hline FRC_PF_5_4 & 284.04 & 327.81 & -15.41 & & 276.85 & 2.53 & \\
\hline FRC_PF_5_5 & 264.60 & 339.79 & -28.42 & & 257.24 & 2.78 & \\
\hline FRC_PF_5_6 & 191.56 & 303.17 & -58.26 & & 156.90 & 18.09 & \\
\hline FRC_PF_9_1 & 316.04 & 357.80 & -13.21 & 33.98 & 300.97 & 4.77 & 12.17 \\
\hline FRC_PF_9_2 & 244.68 & 357.26 & -46.01 & & 283.65 & -15.93 & \\
\hline FRC_PF_9_3 & 273.51 & 353.93 & -29.40 & & 273.19 & 0.12 & \\
\hline FRC_PF_9_4 & 281.29 & 362.19 & -28.76 & & 306.47 & -8.95 & \\
\hline FRC_PF_9_5 & 232.87 & 392.03 & -68.35 & & 296.81 & -27.46 & \\
\hline FRC_PF_9_6 & 246.44 & 291.16 & -18.15 & & 285.41 & -15.81 & \\
\hline FRC_SF_60_5 & 392.48 & 569.95 & -45.22 & 64.02 & 406.43 & -3.55 & 3.79 \\
\hline FRC_SF_60_6 & 313.02 & 572.27 & -82.82 & & 325.61 & -4.02 & \\
\hline FRC_SF_40_1 & 308.22 & 407.38 & -32.17 & 30.26 & 302.25 & 1.94 & 4.28 \\
\hline FRC_SF_40_3 & 304.17 & 406.07 & -33.50 & & 309.15 & -1.64 & \\
\hline FRC_SF_40_4 & 318.95 & 429.98 & -34.81 & & 333.52 & -4.57 & \\
\hline FRC_SF_40_5 & 316.76 & 407.71 & -28.71 & & 306.52 & 3.23 & \\
\hline FRC_SF_40_6 & 304.96 & 372.37 & -22.10 & & 274.36 & 10.03 & \\
\hline UHPFRC_SMF_130_1 & 876.03 & 1315.73 & -50.19 & 90.81 & 867.69 & 0.95 & 12.58 \\
\hline UHPFRC_SMF_130_2 & 469.65 & 1086.90 & -131.43 & & 583.36 & -24.21 & \\
\hline UHPFRC_SMF_157_1 & 986.52 & 1459.72 & -47.97 & 59.93 & 971.96 & 1.48 & 2.08 \\
\hline UHPFRC_SMF_157_2 & 594.55 & 1021.90 & -71.88 & & 610.49 & -2.68 & \\
\hline UHPFRC_SMF_170_1 & 962.80 & 1499.12 & -55.70 & 52.53 & 1036.27 & -7.63 & 6.30 \\
\hline \multirow{2}{*}{ UHPFRC_SMF_170_2 } & 720.10 & 1075.60 & -49.37 & & 684.34 & 4.97 & \\
\hline & & & & 51.11 & & & 6.65 \\
\hline
\end{tabular}


The same table also shows the individual and average errors between the predicted and the measured values.

For most of the specimens, there is a good agreement between the experimental results and the predictions performed with the new model, which present an average error of only $6.7 \%$ for all specimens. On the other hand, the model from Carmona Malatesta et al. (2012) leads to relative errors considerably higher, with an average error of $51.1 \%$.

An explanation of this difference can be that the model from Carmona Malatesta et al. (2012) is only based on an experimental campaign with two types of fibres, different from the ones considered here. On the contrary, the new model is based on the mathematical representation of the physical mechanisms that govern the Barcelona Test, thus being applicable to all types of FRC (fibre type, dosage, etc.).

Notice that both models show results considerably different for the two families of FRC analysed. For conventional FRC the correlations from Carmona Malatesta et al. (2012) show an average error of $38.6 \%$ whereas the new model proposed shows an average error of $6.4 \%$. However, for UHPFRC the average error from Carmona Malatesta et al. (2012) reaches $67.8 \%$ in comparison with the $7.0 \%$ obtained with the new model, which is 9.7 times smaller.

Moreover, the errors of the predictions with the new model for the two families of concrete is quite similar $(6.4 \%$ for conventional FRC and $7.0 \%$ for UHPFRC with high fibre content), despite the big difference between both materials. This indicates that use of the same length of the conical wedge (considered $40 \mathrm{~mm}$ ) and number of cracks (considered 3) for all types of concrete did not compromise the good fit obtained with the new model, regardless of the changes that might occur in the failure mechanism of each family of concrete.

Anyhow, it is important to remark that the new model proposed includes the number of cracks $(n)$ and the length of conical wedge $(l)$ as input variables. These variables should be measured directly in the specimen after the test and then used to perform the correlation. In other words, the model proposed here is completely opened for the user to consider the specific characteristics of each specimen.

\section{Conclusions}

The new model developed in this paper provides a clear physical understanding of the main mechanism observed in the three stages that the specimen undergoes during the Barcelona test.

Based on this, a simple and straightforward analytical model valid for the whole extent of the curve was proposed to directly convert the $\delta$ into the TCOD. This model considers parameters like the length of the cone $(l)$ and the number of cracks $(n)$ that may be measured after the test for each specimen.

The comparison with the experimental result indicate that the model is capable of predicting accurately the entire load-TCOD curve, regardless of the type of concrete (conventional FRC or UHPFRC), of the type of fibre (steel or plastic, micro or macro) and of the post-cracking behaviour (with hardening or with softening). A good agreement between the measured $T C O D$ and the predicted $T C O D$ values was found for all cases.

The average error of the estimation of the toughness in the new model proposed is $6.7 \%$, whereas the experimental equation from Carmona Malatesta et al. (2012) yields an average error 7.6 times higher $(51.1 \%)$ for the same group of specimens.

The results obtained in this paper validate the new model proposed, thus allowing a positive simplification of the Barcelona test that can be performed with control of axial displacement instead of with control of TCOD.

\section{Acknowledgements}

In memory of Professor Luis Agulló, for his outstanding contribution to this project, his unconditional dedication to the teaching of engineers and his unforgettable friendship. The authors would like to thank Berenice Toralles Carbonari for the experimental data provided. The authors acknowledge the support of the Spanish Ministry of Science and Innovation (MICINN) in the scope of the project CONSFIB (reference: BIA 1010-17478). The first and second author acknowledge the grant FPI - UPC provided by the UPC and the grant FI provided by the Comissionat per a Universitats del DIUE de la Generalitat de Catalunya $i$ del Fons Social Europeu, respectively. The first and second authors also acknowledge the support of the Collegi d'Enginyers de Camins, Canals i Ports de Catalunya.

\section{References}

ASTM C-1018: Standard test method for flexural toughness and first-crack strength of fiber-reinforced concrete (using beam with third-point loading). American Society for Testing and Materials, Philadelphia, USA, 1997. 7 p.

Blanco, A.; Pujadas, P.; de la Fuente, A.; Cavalaro, S.; Aguado, A. 2013. Application of constitutive models in European codes to RC-FRC, Construction and Building Materials 40: 246-259.

Bortolotti, L. 1988. Double punch test for tensile and compressive strengths in concrete, ACI Materials Journal 85(1): 26-32.

Carmona Malatesta, S.; Aguado de Cea, A.; Molins Borrell, C. 2012. Generalization of the Barcelona test for the toughness control of FRC, Materials and Structures 45(7): 1053-1069.

http://dx.doi.org/10.1617/s11527-011-9816-8

Chen, W.-F. 1970. Double punch test for tensile strength of concrete, ACI Materials Journal 67(2): 993-995. 
de la Fuente, A.; Pujadas, P.; Blanco, A.; Aguado, A. 2012. Experiences in Barcelona with the use of fibres in segmental linings, Tunnelling and Underground Space Technology 27(1): 60-71. http://dx.doi.org/10.1016/j.tust.2011.07.001

de Montaignac, R.; Massicotte, B.; Charron, J.-P.; Nour, A. 2012. Design of SFRC structural elements: postcracking tensile strength measurement, Materials and Structures 45(4): 609-622. http://dx.doi.org/10.1617/s11527-011-9784-z

Di Prisco, M.; Plizzari, G.; Vandewalle, L. 2009. Fibre reinforced concrete: new design perspectives, Materials and Structures 42(9): 1261-1281. http://dx.doi.org/10.1617/s11527-009-9529-4

EN 14651:2005 Test method for metallic fibered concrete measuring the flexural tensile strength (limit of proportionality (LOP), residual). CEN European Committee for Standardization, 2005. 20 p.

Klein, N. S.; de la Fuente, A.; Aguado, A.; Maso, D. 2011. Lightweight self-compacting concrete reinforced with fibres for slab rehabilitation, Materiales de construcción 61: 239-256.

Molins, C.; Aguado, A.; Marí, A. R. 2006. Quality control test for SFRC to be used in precast segments, Tunnelling and Underground Space Technology 21(3-4): 423-424. http://dx.doi.org/10.1016/j.tust.2005.12.067

Molins, C.; Aguado, A.; Saludes, S. 2009. Double Punch Test to control the tensile properties of FRC (Barcelona test), Materials and Structures 42(4): 415-425. http://dx.doi.org/10.1617/s11527-008-9391-9

NBN B 15-238: Test on fibre reinforced concrete bending test on prismatic simples. Norme Belge, Institut Belge de Normalisation. Brussels, 1992. 24 p.

Parmentier, B.; Vandewalle, L.; Van Rickstal, F. 2008. Dispersion of the mechanical properties of FRC investigated by different bending tests, in Proc. of the
Fib Symposium "Tailor Made Concrete Structures", 19-22 May, 2008, Amsterdam, Netherlands, 507-512.

Pujadas, P.; Blanco, A.; de la Fuente, A.; Aguado, A. 2012. Cracking behaviour of FRC slabs with traditional reinforcement, Materials and Structures 45(5): 707-725. http://dx.doi.org/10.1617/s11527-011-9791-0

Sainz, R. 2010. Uso de la Deformación Axial para Determinar la Tenacidad en Hormigones Reforzados Mediante el Ensayo de Doble Punzonamiento [Using of axial strain for toughness in reinforced concrete by testing double punching]. Memoria de Grado, UTFSM, Valparaíso, Chile.

Serna, P.; Arango, S.; Ribeiro, T.; Núñez, A. M.; GarciaTaengua, E. 2009. Structural cast-in-place FRC: technology, control criteria and recent applications in Spain, Materials and Structures 42(9): 1233-1246. http://dx.doi.org/10.1617/s11527-009-9540-9

Torrents, J. M.; Blanco, A.; Pujadas, P.; Aguado, A.; JuanGarcía, P.; Sánchez-Moragues, M. A. 2012. Inductive method for assessing the amount and orientation of steel fibre in concrete, Materials and Structures 45(10): 1577-1592. http://dx.doi.org/10.1617/s11527-012-9858-6

UNE 83515:2010 Hormigones con fibras. Determinación de la resistencia a fisuración, tenacidad y resistencia residual a tracción. Método Barcelona [Concrete with fibres. Determination of resistance to cracking, toughness and tensile residual. Barcelona method]. AENOR, Spain, 2010. 15 p.

Walraven, J. C. 2009. High performance fibre reinforced concrete: progress in knowledge and design codes, Materials and Structures 42(9): 1247-1260. http://dx.doi.org/10.1617/s11527-009-9538-3

Pablo PUJADAS. PhD candidate at the Department of Construction Engineering at the Universitat Politècnica de Catalunya, Barcelona, Spain. He develops his thesis in the scope of fiber reinforced concrete. His main research interests focuses on properly assess fiber orientation and post-cracking tensile behavior of fiber reinforced concrete by means of different test methods, the creep behavior of cracked specimens and the development of a direct and rational design constitutive models for fiber reinforced concrete structures regarding the orientation of fibers.

Ana BLANCO. PhD candidate at the Department of Construction Engineering, Universitat Politècnica de Catalunya. She develops her thesis in the scope of steel fiber reinforced concrete. Her research focuses on the constitutive models to design fiber reinforced concrete structures, fiber orientation and its influence on the performance of the material and the post-cracking creep behavior of steel fiber reinforced concrete.

Sergio CAVALARO. Assistant Professor of the Department of Construction Engineering at the Universitat Politècnica de Catalunya, Barcelona, Spain. His main research interests are fiber reinforced concrete, shotcrete, selfcompacting concrete, concrete dams and tunnels.

Albert de la FUENTE. A Lecturer, professor in the field of Concrete Structures of the Departament d'Enginyeria de la Construcció at Universitat Politècnica de Catalunya. His main research interests include nonlinear analysis of concrete structures, optimization of fiber reinforced structures and its industrial applications and life cycle assessment (LCA).

Antonio AGUADO. Professor of the Department of Construction Engineering at the Universitat Politècnica de Catalunya, Barcelona, Spain. His main research interests are fiber reinforced concrete, shotcrete, self-compacting concrete, sustainability, value analysis for integral and objective evaluation, concrete dams and tunnels. 